\title{
Suppression of plant defense responses by extracellular metabolites from Pseudomonas syringae pv. tabaci in Nicotiana benthamiana
}

\author{
Seonghee Lee, Dong Sik Yang, Srinivasa Rao Uppalapati, Lloyd W Sumner and Kirankumar S Mysore*
}

\begin{abstract}
Background: Pseudomonas syringae pv. tabaci (Pstab) is the causal agent of wildfire disease in tobacco plants. Several pathovars of Pseudomonas syringae produce a phytotoxic extracellular metabolite called coronatine (COR). COR has been shown to suppress plant defense responses. Interestingly, Pstab does not produce COR but still actively suppresses early plant defense responses. It is not clear if Pstab produces any extracellular metabolites that actively suppress early defense during bacterial pathogenesis.

Results: We found that the Pstab extracellular metabolite extracts (Pstab extracts) remarkably suppressed stomatal closure and nonhost hypersensitive response (HR) cell death induced by a nonhost pathogen, P. syringae pv. tomato T1 (Pst T1), in Nicotiana benthamiana. We also found that the accumulation of nonhost pathogens, Pst T1 and P. syringae pv. glycinea (Psgly), was increased in N. benthamiana plants upon treatment with Pstab extracts. The HR cell death induced by Pathogen-Associated Molecular Pattern (INF1), gene-for-gene interaction (Pto/AvrPto and (f-9/Avr(f-9) and ethanol was not delayed or suppressed by Pstab extracts. We performed metabolite profiling to investigate the extracellular metabolites from Pstab using UPLC-qTOF-MS and identified 49 extracellular metabolites from the Pstab supernatant culture. The results from gene expression profiling of $P R-1, P R-2, P R-5, P D F 1.2, A B A 1$, COl1, and HSR203J suggest that Pstab extracellular metabolites may interfere with SA-mediated defense pathways.
\end{abstract}

Conclusions: In this study, we found that Pstab extracts suppress plant defense responses such as stomatal closure and nonhost HR cell death induced by the nonhost bacterial pathogen Pst T1 in N. benthamiana.

Keywords: Nicotiana benthamiana, Pseudomonas syringae pv. tabaci, Extracellular metabolites, Hypersensitive response (HR), Stomata, Nonhost resistance

\section{Background}

Foliar bacterial phytopathogens such as the Pseudomonas syringae species survive on the plant leaf surface as epiphytes [1]. During the initial infection process, the bacterial pathogens produce virulence factors including effector proteins and secondary metabolites, to inactivate early plant defense responses such as stomata-based immunity [2,3] and hypersensitive response (HR) cell death at the site of infection [4]. The failure of early pathogen recognition delays initiation of the downstream defense cascade and results in the development of disease symptoms in plants. Therefore, the suppression of early plant

\footnotetext{
* Correspondence: ksmysore@noble.org

The Samuel Roberts Noble Foundation, Plant Biology Division, Ardmore, OK 73401, USA
}

(c) 2013 Lee et al.; licensee BioMed Central Ltd. This is an Open Access article distributed under the terms of the Creative Commons Attribution License (http://creativecommons.org/licenses/by/2.0), which permits unrestricted use, distribution, and reproduction in any medium, provided the original work is properly cited.

defense responses is one of the important steps for bacterial pathogens to successfully colonize plant tissues, leading to disease.

It has long been thought that stomata are the passive portal for entry of phytopathogens. However, recent studies demonstrated that stomata play an active role in restricting bacterial invasion as part of the plant innate immune system $[2,5]$. Perception of multiple bacterial pathogen-associated molecular patterns (PAMPs), including flagellin, lipopolysaccharide (LPS) and elongation factor $\mathrm{Tu}(\mathrm{EF}-\mathrm{Tu})$ induces closure of stomata in leaf epidermal peels of Arabidopsis [6]. It is now believed that stomatal closure is a common plant defense response initiated by the perception of bacterial PAMPs and limits bacterial invasion in plants. However, certain bacterial pathogens have evolved to deliver specific virulence factors 
such as coronatine (COR) to overcome PAMP-triggered immunity (PTI) and stomata-based defense.

COR is a nonhost-specific, non-proteinaceous virulence effector produced by several pathovars of $P$. syringae $[7,8]$. This is one of the most extensively studied phytobacterial secondary metabolites that modulate plant hormonal defense signaling and functions as a stomatal-based immunity suppressor. COR has structural and functional similarity to jasmonates including 12-oxo-phytodienoic acid (12-OPDA) and jasmonic acid-isoleucine (JA-Ile), and activates the JA pathway in Arabidopsis and tomato [9-11]. The virulent pathogen P. syringae pv. tomato strain DC3000 (Pst DC3000) produces COR on the plant surface to reopen closed stomata, allowing increased bacterial entry [2,3]. A Pst DC3000 mutant (Pst DC3118) that is deficient in COR production has severely attenuated virulence when dip- or spray-inoculated onto Arabidopsis and tomato leaves [3]. However, this defect can be restored in Arabidopsis mutants (fls2, ost1 and gpa1) that are defective in abscisic acid (ABA)- and PAMP-regulated stomatal closure [12,13].

In contrast to the number of studies done for CORproducing bacterial pathogens, it has been largely overlooked that other pathovars of $P$. syringae without COR may also produce non-proteinaceous virulence factors to suppress plant innate immunity. Xanthomonas campestris pv. campestris $(X c c)$ that has a broad host range including Brassicaceae family is shown to overcome stomatal defense in Arabidopsis [14]. The extracellular metabolite secreted from $X c c$ is regulated by $r p f$ (regulation of pathogenicity factor) gene cluster. The $r p f$ mutant strains of Xcc were unable to reopen stomata, but the stomata closure was reverted when ethyl acetate extracts from $X c c$ culture supernatants were added to the mutant strains in Arabidopsis [14]. Two other P. syringae strains, $P$. s. pv. tabaci (Pstab) and P. s. pv. tomato strain T1 (Pst T1), do not produce $\mathrm{COR}$, but these bacterial strains can actively reopen stomata in tobacco and tomato plants, respectively [3,5].

Hypersensitive response (HR) is another important form of early defense response against bacterial pathogens. HR is associated with defenses that are highly manifested by development of rapid cell death. A number of HR elicitors from bacterial pathogens have been described. Phytobacterial avirulent proteins (Avr) cause HR during incompatible interactions in plants containing corresponding plant resistance $(R)$ genes (gene-for-gene resistance-mediated HR). Protein products of the hrp (hypersensitive response and pathogenicity) gene family cause HR in nonhost plants (nonhost disease resistancemediated HR; nonhost HR). The nonhost HR cell death is the common phenomenon observed in many plants in response to non-adapted bacterial pathogens [15]. The bacterial effector proteins of $P$. syringae are injected into plant cells by the pathogen type III secretion system
(TTSS) to suppress basal resistance in host plants $[16,17]$. The TTSS- and Hrp-deficient mutants cannot elicit nonhost HR cell death or be pathogenic on host plants [18]. Moreover, several effectors from Pst DC3000 play an important role in suppression of the $R$-gene mediated HR in tomato [19-21]. In addition, it has been also shown that the Pst DC3000 effector, AvrPto, suppresses nonhost HR cell death in Nicotiana benthamiana and tomato [22]. We recently showed that COR can also suppress HR induced by a nonhost pathogen in N. benthmaina [23].

In the current study, we report that the extracellular metabolite(s) from Pstab suppresses plant defense responses such as stomata-based immunity and hypersensitive response (HR) cell death. We performed extracellular metabolite profiling of Pstab by ultra high performance liquid chromatography coupled to hybrid quadrupole time-of-flight mass spectrometry (UHPLC-qTOF-MS) and isolated putative metabolites involved in the suppression of early plant defense responses in $N$. benthamiana. The patterns of plant defense gene expression suggest that the SA-mediated defense pathway may be modulated by extracellular metabolites from Pstab.

\section{Results}

Bacterial pathogens, Pstab and Pst T1, suppress early defense responses in their host plants, $N$. benthamiana and tomato, respectively

The early infection processes of Pstab in N. benthamiana and Pst T1 in tomato were determined using GFPuv-expressing bacteria [24]. Five days after spray inoculation, a number of fluorescent spots (bacterial colonization) at infection sites were observed under long-wavelength UV light in $N$. benthamiana with Pstab and in tomato with Pst T1 infection. In contrast, only a few fluorescent spots were detected on $N$. benthamiana leaves infected with Pst T1 and on tomato plants infected with Pstab (Figure 1A). We also observed that both Pstab and Pst T1 can reopen stomata and actively enter into apoplastic space in their respective host plants (Figure 1B). However, most stomata remained closed in tomato when inoculated with a nonhost pathogen, Pstab. Similarly, most $N$. benthamiana stomata remained closed when inoculated with a nonhost pathogen, Pst T1. In addition, the inoculation of Pst T1 induced typical nonhost HR cell death on $N$. benthamiana leaves within $20 \mathrm{hrs}$, while the host pathogen Pstab did not induce any visible cell death at that time point (Figure $1 C$ ). We speculate that the nonhost HR cell death in $N$. benthamiana is triggered either by PAMPs or effectors of the nonhost pathogen, Pst T1. Such PAMP- and/or effector-triggered HR is probably suppressed during Pstab-N. benthamiana interaction, thus resulting in disease symptoms after inoculation. These results suggested that Pstab produces host-specific virulence 


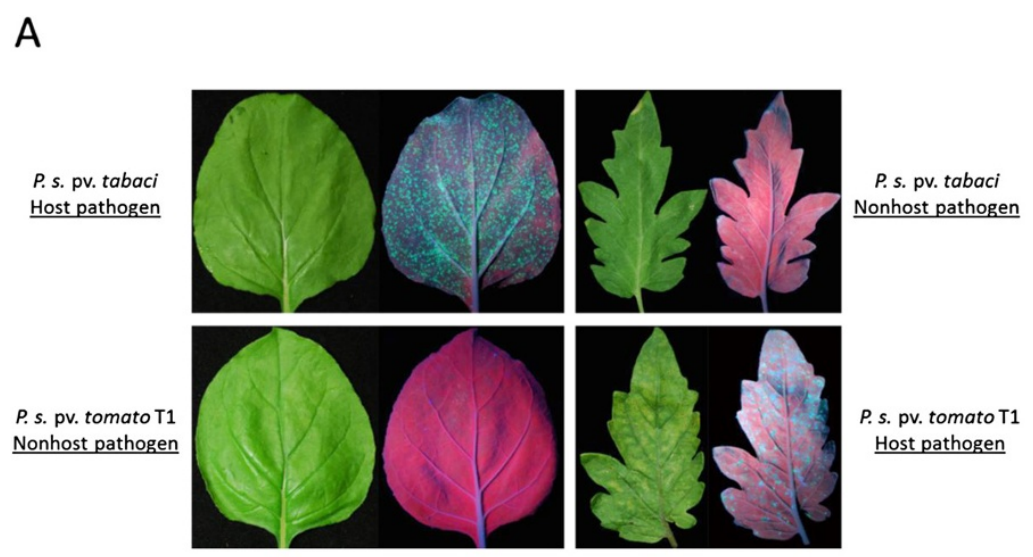

B N. benthamiana

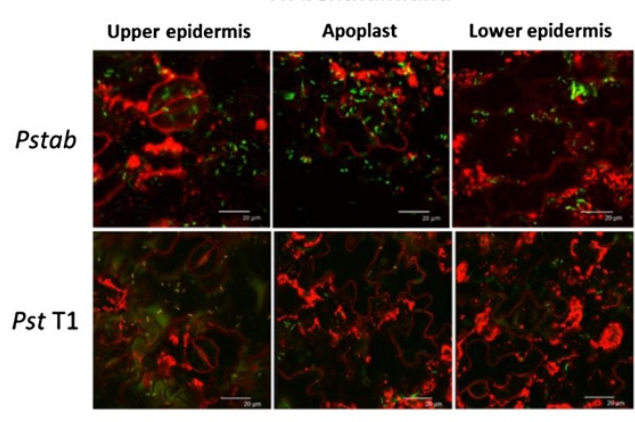

C
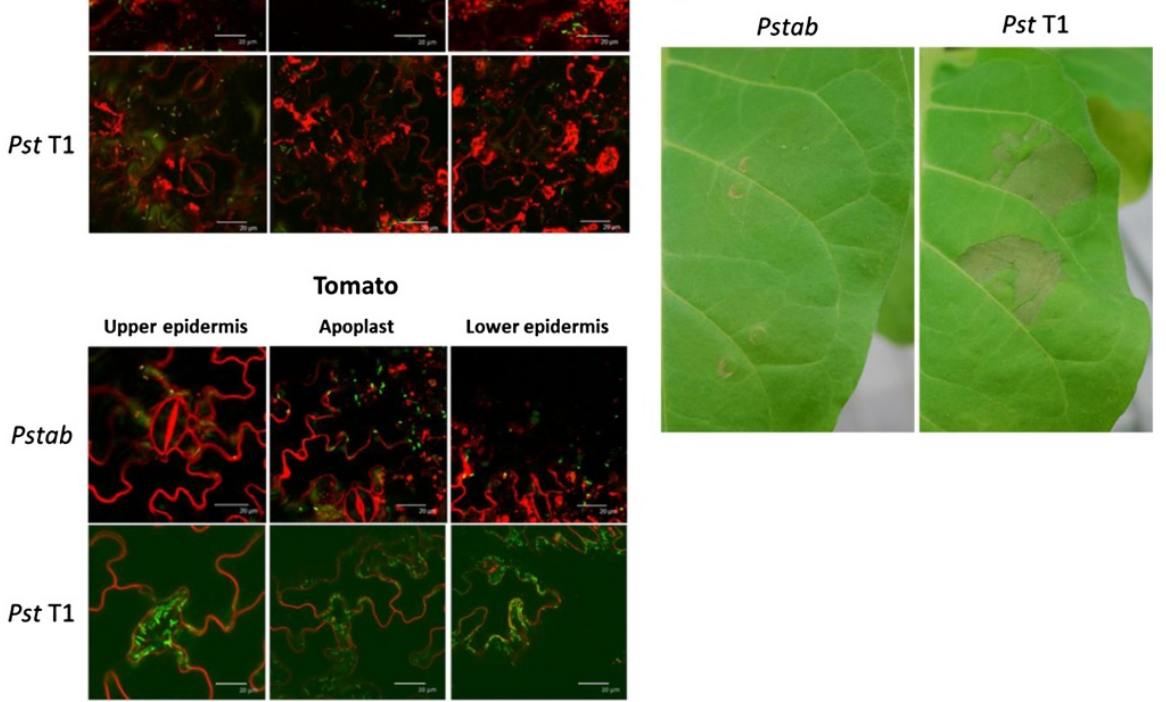

Figure 1 Suppression of stomatal closure and hypersensitive response (HR) cell death by the host bacterial pathogen Pstab in $N$. benthamiana. (A) Inoculation of GFPuv-expressing bacterial pathogen of Pstab $\left(6 \times 10^{3} \mathrm{CFU} / \mathrm{ml}\right)$ in N. benthamiana and Pst T1 (6×10 $\left.\mathrm{CFU} / \mathrm{ml}\right)$ in tomato. Plants were spray inoculated with appropriate bacteria and photographed three days after inoculation. (B) Confocal microscopic images of GFPuv-expressing Pstab and Pst T1 on epidermal peels of N. benthamiana and tomato, respectively. Pstab in N. benthamiana and Pst T1 in tomato were able to reopen stomata $3 \mathrm{hrs}$ after bacterial inoculation, localized around open stomata and in apoplastic space. Epidermal peels were stained with FM4-64 (Invitrogen, Grand Island, N.Y.) to visualize the plasma membrane. Several confocal images were taken from z-series by focusing the stomatal and apoplastic region. (C) Suppression of nonhost HR cell death by Pstab in N. benthamiana. N. benthamiana leaves were syringe-infiltrated with host or nonhost pathogens, Pstab or Pst T1, with a concentration of $2 \times 10^{6} \mathrm{CFU} / \mathrm{ml}$, respectively. Image was taken 16 hours after inoculation.

factor(s) to inactivate stomatal closure and probably suppress PAMP- and/or effector-triggered HR in $N$. benthamiana. This prompted us to investigate if any extracellular metabolite(s) from Pstab can inactivate some plant defense responses.
Extracellular nonpolar metabolites from Pstab suppress stomatal closure induced by the nonhost bacterial pathogen Pst T1

We prepared the Pstab extracts from bacterial culture to investigate whether the observed suppression of stomatal 
defense (shown in Figure 1B) is due to the metabolites secreted out of bacteria. The stomatal closure induced by the nonhost pathogen Pst T1 was suppressed when Pst $\mathrm{T} 1$ was mixed with the extracellular metabolites in the ethyl acetate extract of Pstab culture supernatant prior to inoculation in $N$. benthamiana (Figure 2A). To determine if the metabolites that suppress stomatal closure are extracellular or intracellular products, the Pstab extracts were individually prepared from both the culture supernatant and bacterial cell pellets. Detached $N$. benthamiana leaves were floated on a bacterial suspension of Pst T1 mixed with extracts from either the minimal growth medium (MG; control) or the Pstab supernatant (Pstab sup. ext.), or the Pstab bacterial cell pellet (Pstab cell ext.). The Pst T1 cell numbers in the leaf apoplast were significantly higher (due to more entry of bacteria through stomata) at $4 \mathrm{hrs}$ after incubation of Pst T1 mixed with Pstab supernatant when compared to bacterial numbers in the leaf treated with Pst T1 mixed with Pstab cell extract or the control (Figure 2B). These findings suggest that Pstab supernatant extracts function to suppress stomatal closure. We also detected a slight increase in bacterial entry with cell extract compared to MG extracts, possibly due to the presence of remaining small amounts of Pstab extracellular extracts in bacterial cell pellet.

Pstab extracts suppress hypersensitive response (HR) cell death triggered by nonhost pathogens

Nonhost disease resistance is the common plant defense mechanism which protects plants from various potential pathogens. HR is a common phenomenon for nonhost resistance observed in plant-bacterial pathogen interactions. We further tested whether the metabolites secreted from Pstab (Pstab extracts) can also overcome nonhost HR cell death induced by Pst T1 in N. benthamiana. HR occurred within 16 hrs of syringe infiltration of Pst T1 $\left(2.1 \times 10^{6}\right.$ $\mathrm{CFU} / \mathrm{ml}$ ) in $N$. benthamiana. Interestingly, the nonhost HR cell death was suppressed when Pst T1 was infiltrated along with Pstab extracts. Furthermore, when Pstab extracts alone were infiltrated, there was no visible symptom on the $N$. benthamiana leaf (Figure 3A and $3 \mathrm{~B})$.

To determine if Pstab extracts play a role in virulence, we examined the growth of two nonhost bacterial pathogens, Pst T1 and P. syringae pv. glycinea (Psgly), in the $N$. benthamiana leaves in the presence of Pstab extracts. After co-inoculation of Pst T1 or Psgly with Pstab extracts, the bacterial growth was significantly higher on the inoculated area of both Pst T1 + Pstab extracts and Psgly + Pstab extracts than in the co-inoculated area of Pst T1 or Psgly with MG medium extracts (mock) (Figure 3C and 3D). Since N. benthamiana is a nonhost for both Psgly and Pst T1, their populations gradually decreased two days after inoculation in the mock control. The bacterial populations of Psgly and Pst T1 with Pstab extracts also decreased, but the populations were higher than the population after the mock inoculation. No visible disease symptoms were found in either Psgly + Pstab extracts or Pst T1 + Pstab extracts in the inoculated area of the leaves when compared to mock controls.

To examine the stability of the metabolite, Pstab extracts were treated at $95^{\circ} \mathrm{C}$ for $5 \mathrm{~min}$ and infiltrated with three nonhost bacterial pathogens, P. s. pv. phaseolicola,

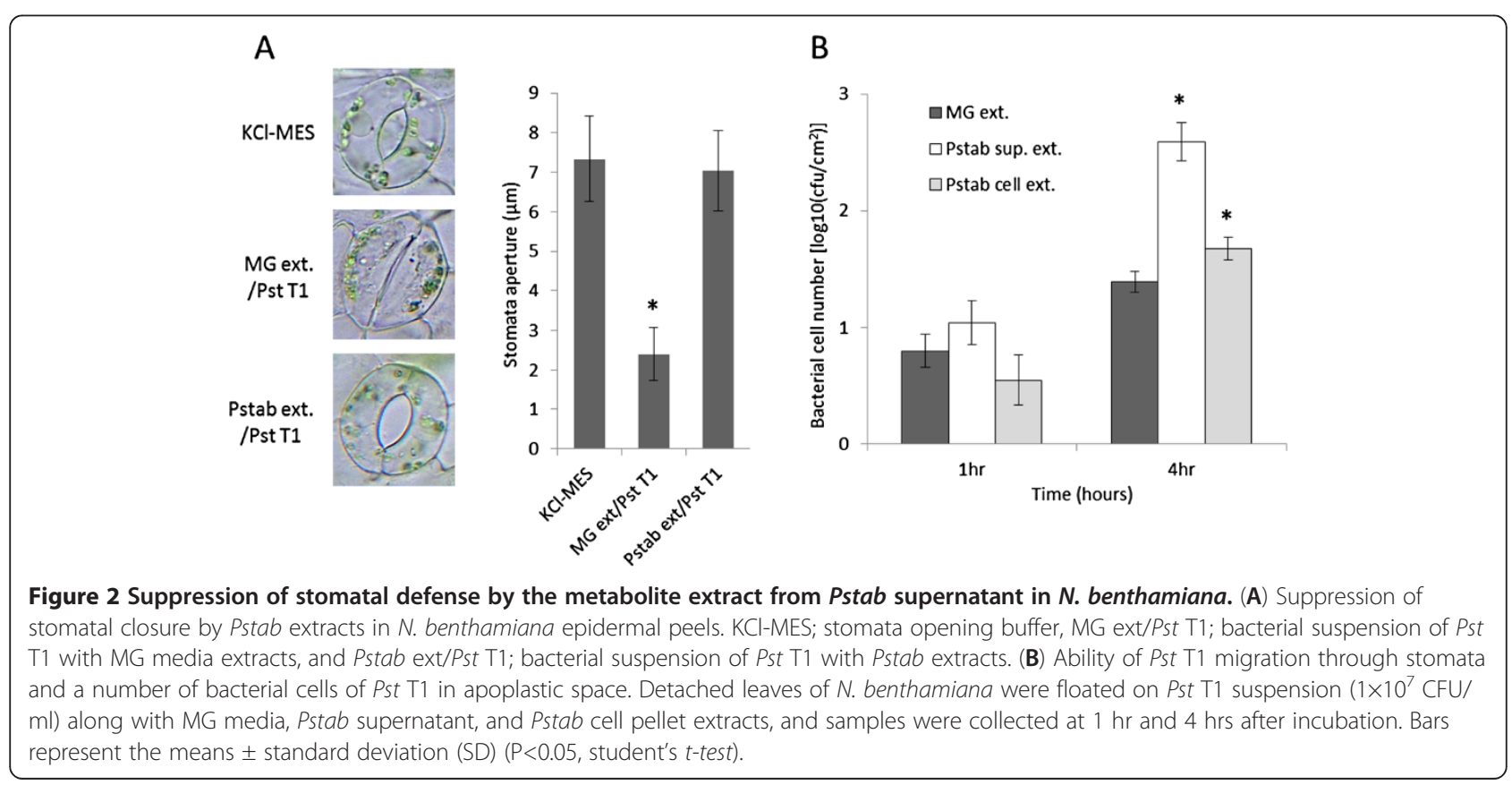


A

HR

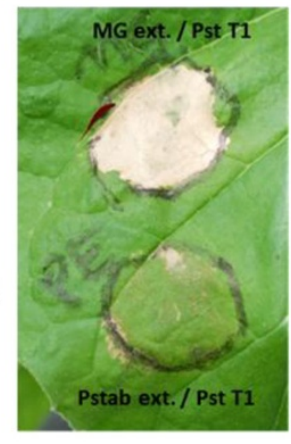

B

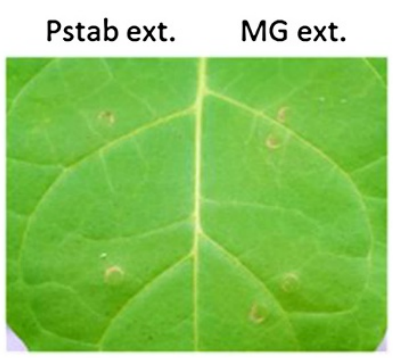

E

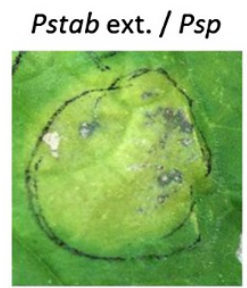

MG ext. / Psp

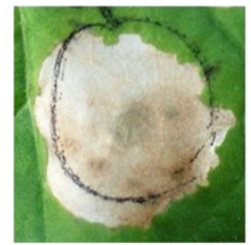

C

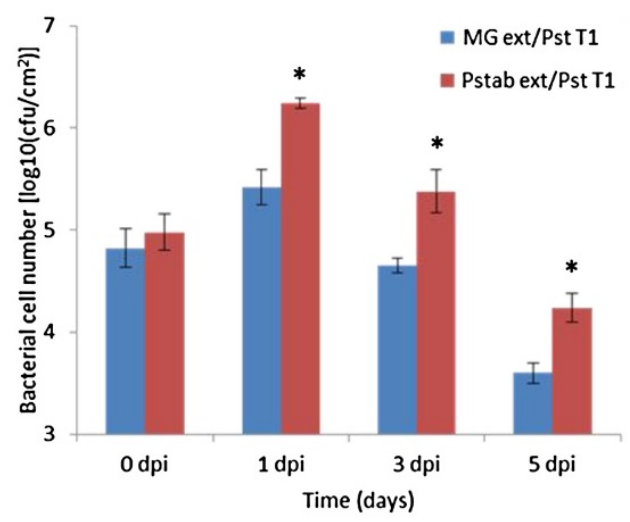

D

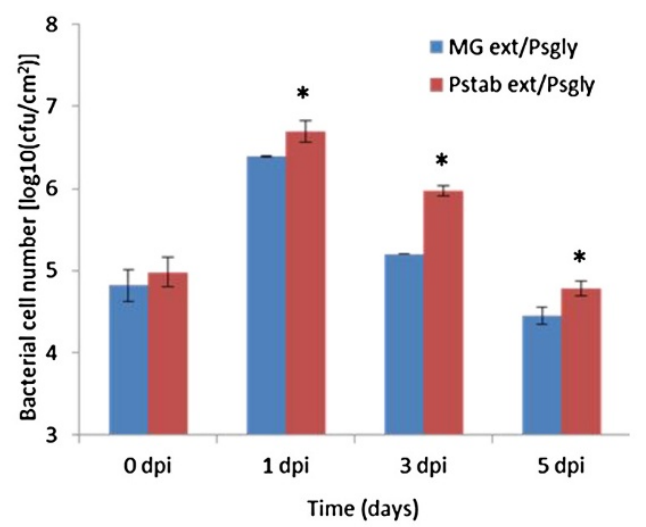

$95^{\circ} \mathrm{C} / 5 \mathrm{~min}$

Pstab ext. / Psm Pstab ext. / Pst T1
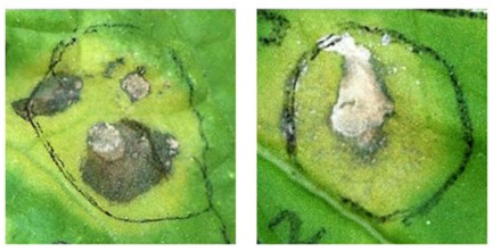

MG ext. / Psm

MG ext. / Pst T1
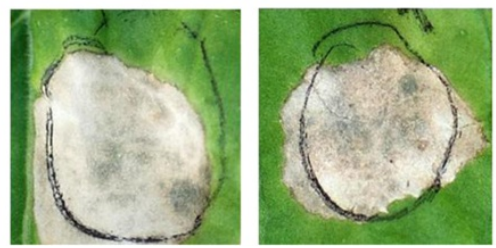

Figure $\mathbf{3}$ (See legend on next page.) 
(See figure on previous page.)

Figure 3 Suppression of nonhost HR cell death and enhancement of bacterial multiplication by Pstab extracts in N. benthamiana. (A) Suppression of nonhost HR cell death by the ethyl acetate extract from Pstab culture supernatant (Pstab ext.). Pst T1 (2.1 x $10^{6}$ CFU/ml) was infiltrated in N. benthamiana leaves, and photo was taken at 48 hpi. (B) Non-phytotoxin activity of Pstab extracts in N. benthamiana leaf. A high concentration of the Pstab extracts was used, $24 \mu \mathrm{l} / \mathrm{ml}$ instead of $6 \mu \mathrm{l} / \mathrm{ml}$. Photographs were taken three days after infiltration. (C and D) Bacterial multiplications of nonhost pathogens P. s. pv. tomato T1 (Pst T1) and P. s. pv. glycinea (Psgly) after inoculation with Pstab extracts in N. benthamiana. Pst T1 (C) and Psgly (D) $\left(3 \times 10^{4} \mathrm{CFU} / \mathrm{ml}\right)$ were inoculated with Pstab extracts, and the bacterial growth was measured. The experiment was repeated twice (three replications for each experiment) with similar results. Bars represent the means \pm standard deviation (SD) $(P<0.05$, student's t-test). (E) Temperature stability of Pstab extracts and suppression of nonhost HR cell death for three nonhost pathogens, $P$. s. pv. phaseolicola (Psp), P. s. pv. maculicola (Psm), and Pst T1. Pstab extracts were boiled (5 min/ $\left.95^{\circ} \mathrm{C}\right)$ and co-infiltrated with the bacterial suspensions. Photographs were taken at $24 \mathrm{hpi}$.

P. s. pv. maculicola and Pst T1. The degree of nonhost HR cell death suppression by the boiled Pstab extracts did not change for all the tested nonhost pathogens (Figure 3E). However, there was cell death at the site of syringe infiltration and chlorosis symptom with the boiled Pstab extracts, suggesting that the virulence factor in the Pstab extracts may be perturbed. To investigate whether Pstab supernatant extracts can suppress $R$ gene- and PAMP-mediated cell death, we transiently expressed $R$-Avr gene combinations, Pto/AvrPto [25] and $C f-9 / A v r C f-9$ [26], in $N$. benthamiana leaves along with Pstab extracts. In addition, we also expressed INF1 (the major secreted elicitin of Phytophthora infestans) [27] that encodes a PAMP and causes cell death on $N$. benthamiana along with Pstab extracts. The development of cell death (HR) was monitored from 24 hrs after the inoculations. Interestingly, Pstab extracts did not suppress or reduce the intensity of cell death observed for both $R$-Avr-gene- and PAMP-induced HR (Figure 4). In addition, chemically induced cell death (20\% EtOH) was also not affected by Pstab extracts, suggesting that Pstab extracts specifically suppress nonhost HR cell death (Figure 4).

\section{Metabolite profiling of the extracellular metabolites from Pstab}

To further prove that Pstab can secrete metabolites into the growth media, we performed metabolite profiling of the Pstab culture media using UHPLC-qTOF -MS (Figure 5A). The extracts of the Pstab culture media contained secreted metabolites from Pstab as well as MG medium. A total of 49 extracellular metabolites from Pstab were detected after subtracting metabolites present in MG medium (Figure 5B). The extracellular metabolite profiling includes the retention time, specific ion $(\mathrm{m} / \mathrm{z})$ and relative intensity used to differentiate unique metabolites; however, they were not chemically annotated (Additional file 1: Table S1). In particular, M39 with the most abundant ion 1080.7322 (m/z) was quantitatively the major metabolite in the extracellular metabolites of Pstab.

\section{Altered expression of defense-related genes by Pstab extracts}

SA has been shown to play a role in HR cell death. We determined the gene expression of PR1, PR2 and PR5 to dissect the involvement of Pstab extracts in the SA-

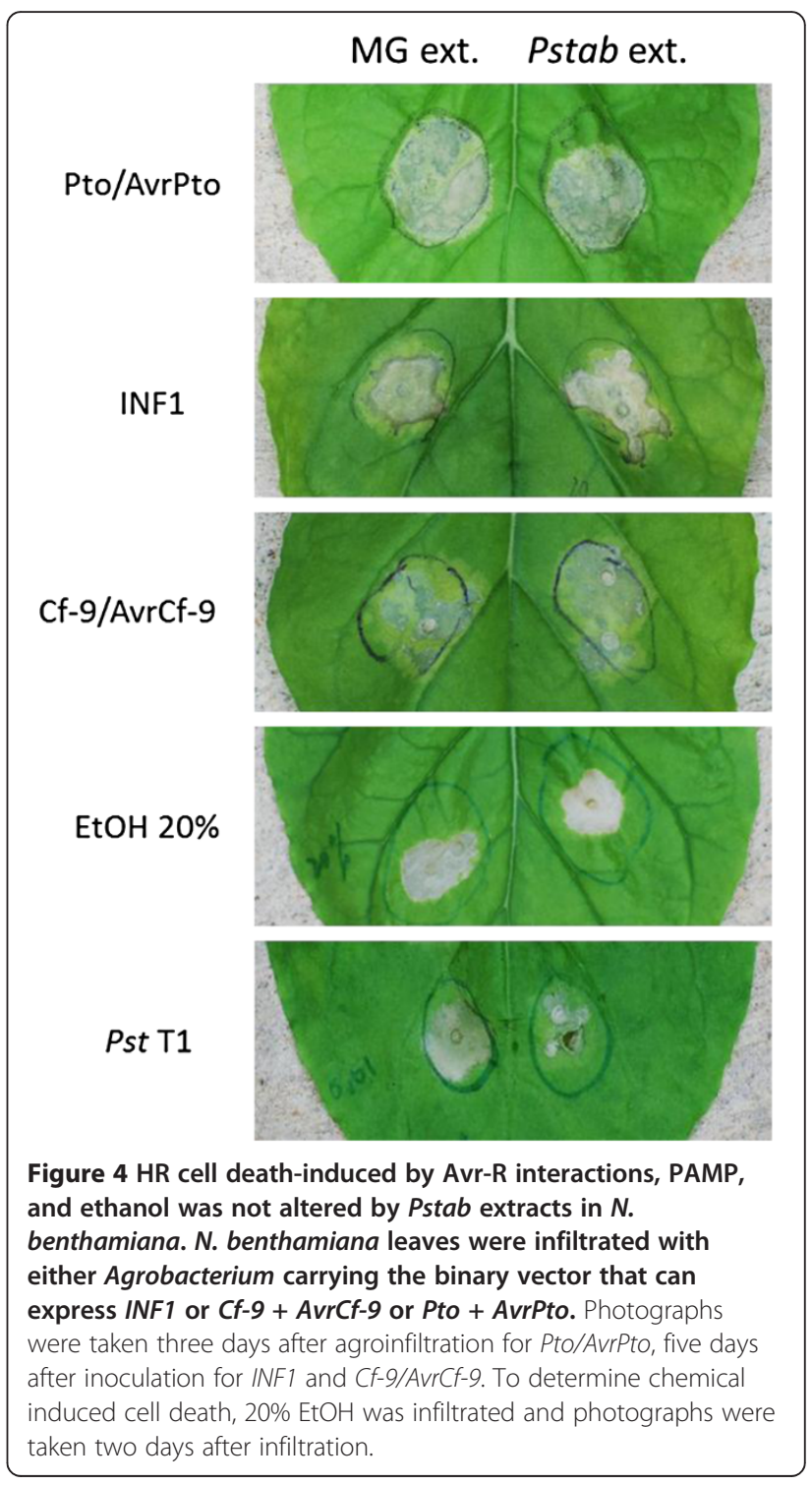




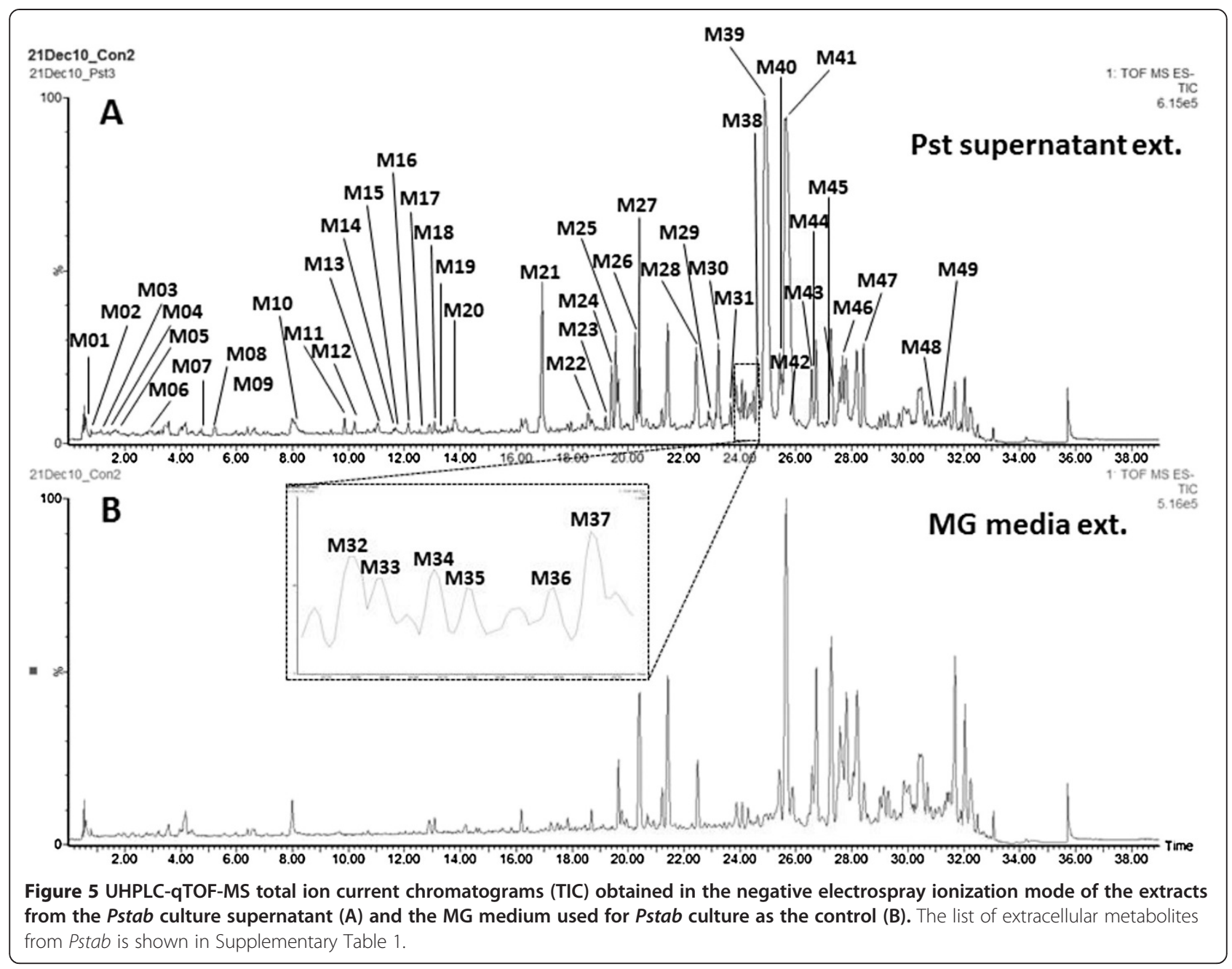

mediated defense pathway. The expression of the PR5 gene was slightly induced in $N$. benthamiana leaves at 6 and $12 \mathrm{hrs}$ after treatments of MG extracts and Pstab extracts. We didn't examine for the expression of $P R 1$ and PR2 after treatments of MG extracts and Pstab extracts. The elevation of the PR5 expression without Pst $\mathrm{T} 1$ inoculation may be related to wounding stress by syringe infiltration. However, when treated with Pst T1, the expression level of PR1, PR2 and PR5 was significantly induced. Strikingly, the accumulation of $P R 1, P R 2$ and PR5 gene transcripts was significantly reduced in $N$. benthamiana leaves when the Pstab extracts were mixed with Pst T1 (Figure 6 and Additional file 2: Figure S1). We examined the expression level of HSR203J, the marker gene for cell death [28], after Pst T1 inoculation. The expression level of HSR203J was not different among samples treated with MG extracts or Pstab extracts without Pst T1 (Additional file 2: Figure S1). However, the expression level of HSR203J was significantly increased after Pst T1 inoculation but the induction of HSR203J was much lower at 6 hpi when Pst T1 was inoculated with Pstab extracts, suggesting that Pstab extracts delay the signaling for nonhost pathogen induced-HR cell death (Figure 6). Although, we didn't observe any visible cell death at the site of infiltration of Pst T1/Pstab extracts, the level of HSR203J expression in Pst T1/Pstab extracts was similar with Pst T1/MG extracts at $12 \mathrm{hpi}$. These results suggest that Pstab extracts down-regulate SA-mediated early defense to suppress nonhost HR cell death. To determine if JA signaling is altered by Pstab extracts, the expression of plant defensin (PDF1.2), a marker for the JA signaling pathway, was examined. The expression level of PDF1.2 was increased rapidly by $12 \mathrm{hrs}$ in leaves infiltrated by MG extracts due to wound stress by syringe infiltration, while the expression level with Pstab extracts alone remained little changed during the experiment (Additional file 2: Figure S1), suggesting that the Pstab extracts suppress even the wound induced defense response. When Pst T1 was inoculated with MG extracts and Pstab extracts, the transcripts of PDF1.2 were increased at $6 \mathrm{hpi}$ and declined at 12 hpi (Figure 6). The expression pattern was not significantly different between Pst T1 + MG extracts and Pst 


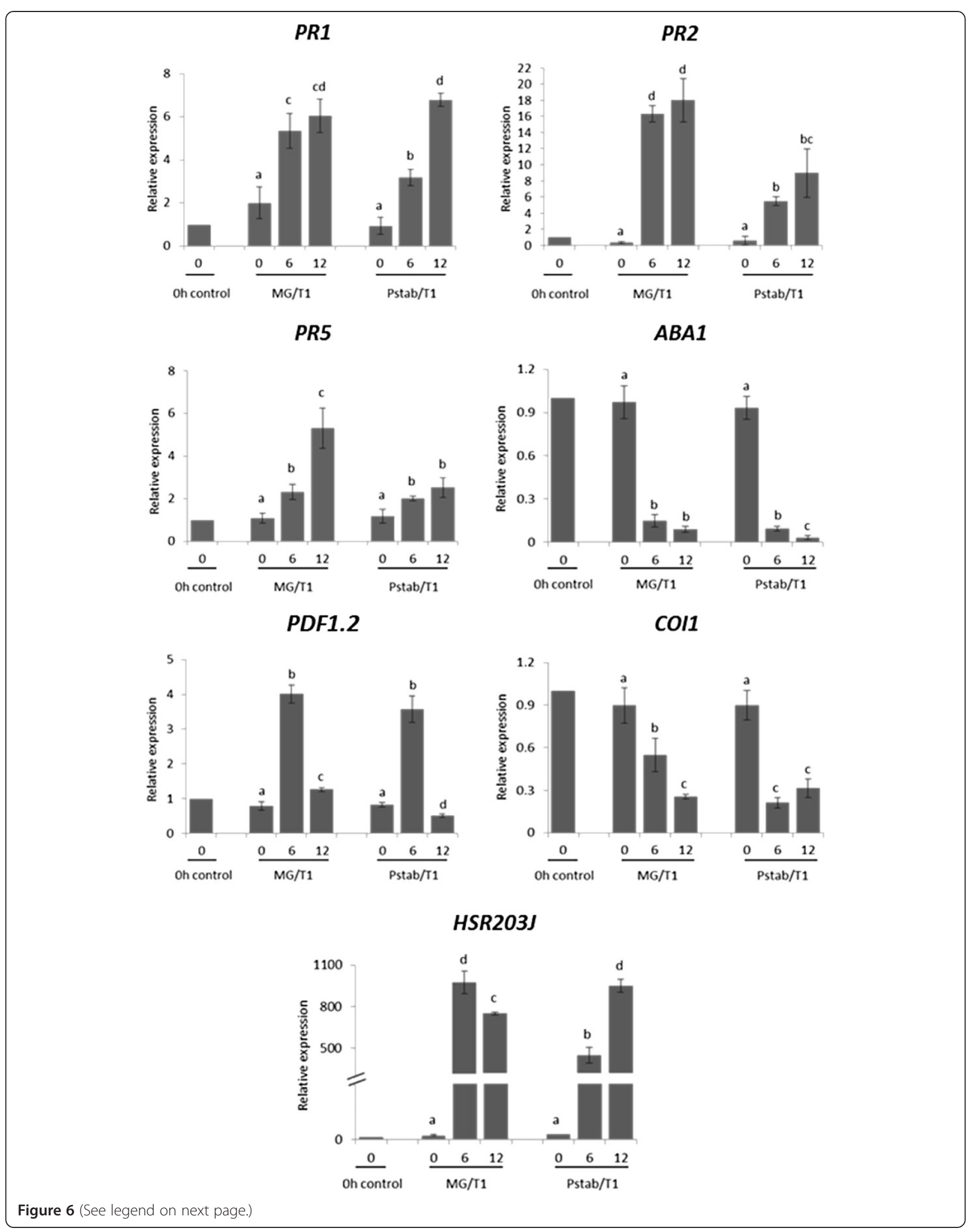


(See figure on previous page.)

Figure 6 Expression patterns of PR1, PR2, PR5, PDF1.2, ABA1, COI1 and HSR203J genes after inoculation with Pst T1 + Pstab extracts in $\boldsymbol{N}$. benthamiana. The expression level of PR1, PR2, PR5, PDF1.2, ABA1, COl1 and HSR203J was determined by qRT-PCR after inoculation of PSt T1 with MG medium extracts or Pstab extracts in N. benthamiana. Gene expression analyses were performed using three biological replications, where each biological replicate consists of three technical replicates. Bars represent the means \pm standard deviation (SD).). Same letters above bars indicate no statistically significant difference $(P<0.05)$ among plant genotypes for a given time point using one-way ANOVA followed by LSD test analysis. The qRT-PCR data were normalized to NbActin transcript and shown as relative to that of target gene expressions in 0 hr $N$. benthamiana leaves without any treatment.

$\mathrm{T} 1+$ Pstab extracts, suggesting that the JA-mediated defense signaling pathway against bacterial pathogen may not be directly modulated by Pstab extracts, in contrast to the SA-mediated pathway.

It has been known that coronatine insensitive 1 (COI1) gene is involved in the stomatal defense in response to bacterial pathogens [2]. Thus, we examined the gene expressions of COI1 to determine if Pstab extracts target the expression of this gene. The level of expression of COI1 gradually decreased upon infiltration of MG extracts and Pstab extracts alone (Additional file 2: Figure S1). This finding agrees with the results of Arabidopsis gene expressions data in the eFP Browser (http://bar.utoronto.ca/efp/cgi-bin/efpWeb.cgi) that the gene expressions are down-regulated 6 and 12 hrs after distilled water infiltration in Arabidopsis. After nonhost pathogen Pst T1 inoculation, COI1 gene was significantly down-regulated by Pstab extracts at 6 hrs post inoculation. However, COI1 expression pattern with Pst T1 inoculation appeared similar to that of the COI1 expression pattern upon infiltration of MG extracts and Pstab extracts alone (Figure 6; Additional file 2: Figure S1). This finding indicates that COI1 expression is decreased at 6 hpi by Pstab extracts and may interfere with the COI1-mediated defense pathway.

Abscisic acid (ABA) is the critical phytohormone for regulating stomatal opening and closure. $A B A 1$ is induced by $\mathrm{ABA}$ and a marker gene for the ABA signaling pathway. The expression of $A B A 1$ was similar to that of COI1 where in the expression was down-regulated upon infiltration with MG extracts and Pstab extracts alone (Additional file 2: Figure S1). In Arabidopsis, $A B A 1$ expression is reduced $6 \mathrm{hrs}$ after water or buffer infiltration (http://bar.utoronto.ca/efp/cgi-bin/efpWeb.cgi). Pst T1 infection did not alter the expression of $A B A 1$ compared to infiltration with MG extracts and Pstab extracts alone (Figure 6; Additional file 2: Figure S1). In addition, the expression pattern of $A B A 1$ was not significantly different among Pst T1 + MG extracts inoculated leaves and Pst T1 + Pstab extracts inoculated leaves.

\section{Discussion}

Studies on the mechanisms of bacterial elicitation of early plant defense responses have unraveled important questions during plant-pathogen interactions [29-31]. It is remarkable that bacteria have evolved to deliver diverse virulence factors to defeat sophisticated plant defense systems [30,32]. Apart from the numerous proteinaceous effectors that the bacteria can deliver into plants, COR is the first discovered virulence metabolite secreted from several $P$. syringae strains and can suppress plant defense responses [2,7,10,33-35]. However, we still don't know whether other non-COR-producing pathovars of $P$. syringae produce metabolites that have virulence function. It is still not clear how extracellular metabolites from bacterial pathogens can suppress plant defense responses.

In this study, we showed that extracellular metabolites from the non-COR producing Pseudomonas syringae pathogen, Pstab, can suppress plant defense responses including stomatal closure and nonhost HR cell death in $N$. benthamiana. Most stomata in epidermal peels of $N$. benthamiana close within 3 hrs upon inoculation with the nonhost pathogen Pst T1. Both Pst T1 and Pstab do not produce COR (due to lack of genes involved in biosynthesis of COR), but they can still reopen stomata in their respective host plants (Figure 2). We demonstrated that Pstab extracts suppress stomatal defense in $N$. benthamiana; however, it is unknown how Pst T1 suppresses stomatal defense in tomato. COR has been shown to suppress stomatal closure in Arabidopsis [2,12], and this is important for a virulent bacterium to enter the leaf apoplast. Interestingly, when a nonhost pathogen, Pst T1, was inoculated on $N$. benthamiana with Pstab extracts, the stomatal closure induced by Pst T1 was suppressed (Figure 2). This finding suggests that the non-COR-producing strain Pstab may produce other uncharacterized extracellular metabolites that may have a similar function as COR in opening stomata.

We also found that the nonhost HR cell death induced by Pst T1 in $N$. benthamiana was also suppressed when inoculated with Pstab extracts (Figure 3). It has been known that Pstab produces tabtoxin that induces chlorosis and is associated with the symptoms of wildfire disease on tobacco and halo blight of oats [36]. Tabtoxin is a dipeptide which is not biologically active and needs to be hydrolyzed by peptidase for an active toxic component, tabtoxinine- $\beta$-Lactam $(\mathrm{T} \beta \mathrm{L})$. T $\beta \mathrm{L}$ is released by zinc-dependent aminopeptidases in the periplasm of the bacterium or by enzymes in the plant cell, and inhibits the enzyme glutamine synthetase that results in chlorosis 
$[37,38]$. Raaijmakers et al. [39] described that T $\beta \mathrm{L}$ is proved to be difficult to synthesize due to the toxin's instability. Tabtoxin is a relatively unstable molecule in vivo and during the procedures of toxin purification [40,41]. It has been demonstrated that the biological activity of a tabtoxin solution decreases with a half-life of approximately one day at room temperature [41]. In addition, chlorosis is the most characteristic symptom of tabtoxin in tobacco leaves [42]. We, therefore, hypothesized that Pstab extracts does not contain tabtoxin. To prove that metabolites but not active proteins play a role in stomata opening and HR suppression, the Pstab culture supernatant was extracted using an organic solvent, ethyl acetate with $1 \%$ formic acid. The process of ethyl acetate extraction removes peptides from Pstab. We also examined whether the Pstab extracts have any toxic activity in $N$. benthamiana leaves. The inoculated leaves did not produce any visible symptoms contrary to tabtoxin that produces yellowing (Figure 3A) [43].

$P$. syringae pathovars produce several non-effector type virulence factors such as tabtoxin, phaseolotoxin, mangotoxin, and COR [7]. All these phytotoxins except COR are made of small peptide molecules. COR is a non-proteinaceous phytotoxin that is involved in stomata opening and suppressing SA-dependent host defense responses [35]. COR was isolated from P. syringae pv. tomato using HPLC fractionation [7]. However, we used a metabolomics approach to isolate bioactive metabolite(s) from Pstab extracts using UHPLC-qTOF-MS for metabolite profiling. The metabolite profiling determined the total number of metabolites secreted from Pstab in the bacterial culture. This metabolite profiling technique has been effectively used to isolate metabolites differentially expressed in different bacterial strains [44]. Since there were not a large number of metabolites (Figure 5), we can further examine bioactive metabolite(s) which can suppress stomatal closure and nonhost HR cell death using HPLC fractionation. The identification of the Pstab extracellular metabolite(s) that suppresses early plant defense responses in the future will advance our understanding of bacterial pathogen-plant infections.

Salicylic acid (SA) is an important plant hormone for regulating defense responses like stomatal closure and HR $[3,45]$. The bacterial growth of both nonhost pathogens, Psgly and Pst T1, was significantly higher in $N$. benthamiana when they were co-inoculated with Pstab extracts (Figure 3). This could be due to suppression of SA-mediated early defense signaling (Figure 6) by Pstab extracts or due to the suppression of HR. The level of nonhost bacterial population gradually decreased three days after inoculation, and no disease symptoms appeared on the inoculated leaves (Figure $3 \mathrm{~A}$ and $3 \mathrm{~B}$ ) suggesting that Pstab extracts suppress only early defense responses but do not function as pathogenicity factors.
We determined whether Pstab extracts also modulate the jasmonic acid (JA)-mediated defense pathway by examining the level of PDF1.2 and COI1 gene expression. The bacterial virulence factor COR stimulates the JA pathway, thereby suppressing the SA pathway in Arabidopsis and tomato [11,35]. It has been shown that COR targets COI1 (F-box subunit of the SCFCOI1 ubiquitin ligase)/JAI1 (Jasmonic Acid Insensitive 1)-dependent pathways to promote suppression of stomatal-based immunity $[3,46]$. JAZ proteins are repressors of JA signaling, and few JAZ proteins (JAZ1, JAZ3, and JAZ9) have been shown to interact with COI1 [47]. It has also been shown that COI1 plays a role in plant cell death during plantmicrobe interaction. When COI1 was silenced in $N$. benthamiana, cell death-induced by potato virus $\mathrm{X}(P V X)$ was accelerated [48]. Devadas et al. [49] reported that a hrl1 (hypersensitive response-like lesions 1) coil double mutant exacerbated cell death lesions, suggesting that COI1 is necessary for cell death limitation.

Interestingly, in our study, we observed that nonhost HR cell death was suppressed by Pstab extracts, but not for any of the specific R-AVR or PAMP triggered cell death. It is possible that the unknown metabolite in Pstab extracts may specifically inhibits the defense mechanism involved in nonhost resistance. Further studies should be performed to isolate the metabolite and identity its function for the suppression of nonhost HR cell death in response to bacterial pathogens.

\section{Conclusions}

It is demonstrated here that another Pseudomonas pathogen, Pstab that does not produce COR, can still actively suppress stomatal defense and nonhost HR cell death in $N$. benthamiana. This finding clearly suggests that Pseudomonas syringae strains can produce metabolite(s) other than COR to suppress plant defense responses. Isolation and characterization of the Pstab extracellular metabolite(s) will facilitate a better understanding of strategies used by bacterial pathogens to cause disease in host plants.

\section{Methods}

\section{N. benthamiana growth}

$N$. benthamiana was sowed on soilless potting mix BM7 (Berger Co., Quebec, Canada) and grown in a growth room at 22 to $25^{\circ} \mathrm{C}$ for two weeks under a $12 \mathrm{hr}$ photoperiod with light intensity ranging from 300 to $400 \mu \mathrm{mol}$ $\mathrm{m}^{-2} \mathrm{~s}^{-1}$. Two-week-old seedlings were transplanted to 10 $\mathrm{cm}$ diameter round pots containing potting soil (BM7) (Berger Co., Quebec, Canada), with one plant per pot, and grown in the greenhouse at $23^{\circ} \mathrm{C}$ with $16 \mathrm{hrs}$ of extended day-light and supplemental lighting at $100 \mu \mathrm{mol}$ $\mathrm{m}^{-2} \mathrm{~s}^{-1}$. Plants were regularly fertilized (20-10-20). 
Three- to four-week-old $N$. benthamiana plants were used for the experiments.

Seeds of tomato (Solanum lycopersicum cv. Glamour) were obtained from Stokes Seeds Inc (Buffalo, NY, USA). Plants were grown in Scott-200 ${ }^{\circledR}$ mix (The Scotts Co., Marysville, Ohio, U.S.A.) and maintained in growth chambers $\left(24^{\circ} \mathrm{C}, 40-70 \% \mathrm{RH}, 12 \mathrm{~h}\right.$ photoperiod, photon flux density of $150-200 \mu \mathrm{mol} \mathrm{m} \mathrm{sec}^{-1}$ ). Three-week-old seedlings were transplanted to $10 \mathrm{~cm}$ diameter round pots and maintained the same as the $N$. benthamiana plants described above.

\section{Metabolite extracts from the Pstab culture supernatant}

To extract metabolites secreted from Pstab, we followed the extraction method used for COR with minor modifications [50]. The bacterial strain Pstab was grown on a KB plate containing appropriate antibiotics. A single colony of Pstab was incubated in $10 \mathrm{ml}$ of ManitolGlutamate (MG) medium (manitol, $10 \mathrm{~g}$; L-glutamic acid, 2 g; $\mathrm{KH}_{2} \mathrm{PO}_{4}, 0.5$ g; $\mathrm{NaCl}, 0.2$ g; $\mathrm{MgSO} 4,0.2$ g with $\mathrm{pH} 7 /$ liter) at $28^{\circ} \mathrm{C}$ with $250 \mathrm{rpm}$ for $48 \mathrm{hr}$. The $2.5 \mathrm{ml}$ of Pstab culture was added to $47.5 \mathrm{ml}$ fresh MG medium and cultured for six days at $18^{\circ} \mathrm{C}$ with $220 \mathrm{rpm}$ in a rotary shaker. The Pstab cultures $(150 \mathrm{ml})$ were centrifuged for $30 \mathrm{~min}$ at $3,700 \times g$ at $4^{\circ} \mathrm{C}$, and the supernatant was transferred to a sterile glass tube. The Pstab cell pellets were used for analysis of intracellular metabolites and the supernatant for analysis of extracellular metabolites. For extraction of intracellular metabolites, the Pstab cell pellets were placed in a glass vial with $5 \mathrm{ml}$ ethyl acetate containing $1 \%(\mathrm{v} / \mathrm{v})$ formic acid and then sonicated for 20 min. The ethyl acetate fraction was collected through centrifugation $(3,700 \times g, 30 \mathrm{~min})$ and completely dried, using $\mathrm{N}_{2}$ gas. For extraction of extracellular metabolites, the Pstab supernatant was extracted with ethyl acetate containing $1 \%$ formic acid. The ratio of the culture supernatant to the acidified ethyl acetate was 3:5. The ethyl acetate fraction was collected and completely dried, using $\mathrm{N}_{2}$ gas. The MG medium without Pstab was extracted as a control, following the above procedures. The dried extracts were resuspended in $600 \mu \mathrm{l}$ of $16.7 \%$ methanol in $\mathrm{H}_{2} \mathrm{O}$. For stomatal and nonhost HR cell death bioassays, 6 $\mu \mathrm{l}$ of extracts were used for every milliliter of inoculation buffer (10 mM MES, pH 6.5).

\section{Assays for suppression of stomatal closure by Pstab extracts}

Pst $\mathrm{T} 1$ was grown in $\mathrm{KB}$ medium overnight at $28^{\circ} \mathrm{C}$. The bacterial culture was centrifuged at $3,500 \mathrm{rpm}$ for 10 min and resuspended in nanopure water at a concentration of $1 \times 10^{7} \mathrm{CFU} / \mathrm{ml}$. For assay of the bacterial migration through stomata, detached $N$. benthamiana leaves were floated on a bacterial suspension of Pst T1 containing MG media extract or the Pstab extracts for 1 to $4 \mathrm{hrs}$.
After the incubation, leaf disks were collected and a number of bacterial cells in the apoplast were examined. This experiment was repeated three times under the same conditions. For stomatal closure assay, we followed the epidermal peel assay as described [2,14]. To assure that most stomata are open before beginning experiments, plants were kept under light for $3 \mathrm{hrs}$, and the epidermis of $N$. benthamiana leaves was peeled off and immediately floated on stomata opening buffer (10 mM MES-KOH, $30 \mathrm{mM}$ $\mathrm{KCl}$, pH6.3) for 3 hrs. At various time points, the epidermal peels were treated with pathogens, chemicals and bacterial secreted metabolites. An average of 100 random stomatal apertures was measured each treatment, and three samples were collected from each experiment with two replications.

\section{Assays for suppression of nonhost HR cell death by Pstab extracts}

Five $P$. syringae species, one host (Pstab) and four nonhost pathogens [Pst T1, P. s. pv. glycinea (Psgly), P. s. pv. phaseolicola (Psp) and P. s. pv. maculicola (Psm)] were used for this experiment. The bacterial pathogens were cultured in $\mathrm{KB}$ medium with appropriate antibiotics overnight at $28^{\circ} \mathrm{C}$ on a rotary shaker $(250 \mathrm{rpm})$. Bacteria were collected by centrifugation (3500 rpm/10 min) and resuspended in MES buffer (MES $10 \mathrm{mM}, \mathrm{pH}$ 6.5). The bacterial suspension was syringe-infiltrated to fully expanded $N$. benthamiana leaves for determining bacterial growth (for Psgly) and nonhost HR cell death (for Pst T1). To determine whether the bacterial growth is promoted by Pstab extracts, the nonhost pathogen Psgly that does not induce HR cell death was inoculated with either MG medium or the Pstab extracts. The bacterial population in the apoplast was examined for $0,1,3$ and 5 days. For nonhost HR cell death assay, each metabolite sample was infiltrated with Pst T1 using a needle-less syringe on sixweek-old $N$. benthamiana leaves. We selected fully extended upper leaves for the inoculation. In all experiments, the extracts from Pstab supernatant and MG medium were included as positive and negative controls. To eliminate any contaminating proteins in Pstab extracts, the extracts were treated at $95^{\circ} \mathrm{C}$ for $5 \mathrm{~min}$. Two additional nonhost bacterial pathogens, Psp and Psm, including Pst T1 were inoculated along with the boiled Pstab extracts in $N$. benthamiana. Symptoms of nonhost HR cell death were determined from $12 \mathrm{hrs}$ to $72 \mathrm{hrs}$ after inoculation.

To determine the specificity of Pstab extracts suppressing nonhost HR cell death, we used several Avr-R gene combinations (35S:AvrPto-35S:Pto and 35S:Avr9-35S: Cf9) [51,52]. Agrobacterium containing the respective constructs were cultured in $5 \mathrm{~mL} \mathrm{LB}$ medium containing respective antibiotics for $24 \mathrm{hr}$ at $28^{\circ} \mathrm{C}$. The bacterial culture was centrifuged at 1,500 $\mathrm{g}$ for $10 \mathrm{~min}$ and resuspended in $5 \mathrm{~mL}$ of infiltration buffer $(10 \mathrm{mM}$ morpholinoethane 
sulfonic acid (MES) and $200 \mathrm{mM}$ acetosyringone). Then, the culture was incubated at room temperature for three to five hrs. After incubation, bacterial cells were harvested by centrifugation and diluted to $5 \times 10^{5} \mathrm{CFU} / \mathrm{ml}$ (infl, Pto, and AvrPto) and $2 \times 10^{7} \mathrm{CFU} / \mathrm{ml}(C f 9$ and $A v r C f 9$ ) for infiltration. Pto and AvrPto, and Cf9 and AvrCf9 constructs were mixed to $1: 1$ ratio before infiltration to $N$. benthamiana leaves.

\section{Metabolite profiling of the Pstab supernatant extracts}

The dried Pstab extracts were resuspended in $150 \mu \mathrm{l}$ of $80 \%$ methanol in $\mathrm{H}_{2} \mathrm{O}$ and analyzed using a UHPLC-ESI (-)-qTOF-MS instrument (Waters Premier qTOF) with a reverse-phase column (ACQUITY UPLC ${ }^{\text {mi }}$ BEH C18 $1.7 \mu \mathrm{m}, 2.1 \mathrm{~mm} \times 150 \mathrm{~mm}$ ), which was maintained at $60^{\circ} \mathrm{C}$, and components were eluted using a multi-step gradient from 95 to $30 \%$ A (eluent A, $0.1 \%$ aqueous acetic acid) over $30 \mathrm{~min}, 30$ to $5 \%$ over $3 \mathrm{~min}$ and 5 to $95 \% \mathrm{~A}$ over $3 \mathrm{~min}$ at a flow rate $0.56 \mathrm{~mL} / \mathrm{min}$. The complementary eluent $\mathrm{B}$ was acetonitrile. TOF-MS spectra were acquired under the following conditions: spectral acquisition rate: 3.13 per second; detector voltage: $2600 \mathrm{~V}$; threshold: 2037; ESI: $-4500 \mathrm{~V}$; desolvation temperature: $300^{\circ} \mathrm{C}$; nebulizer pressure: $350 \mathrm{kPa}$; interface: $100^{\circ} \mathrm{C}$. Mass measurement accuracy was within $20 \mathrm{ppm}$. The MS system was calibrated using sodium formate, and raffinose was used as the lock mass for internal calibration. Data obtained from metabolite analyses were processed using MarkerLynx 4.1 (Waters) for accurate data mass extraction. Relative abundance was normalized by dividing each peak area by the value of the internal standard peak area.

\section{Determination of defense signaling modulated by Pstab extracts}

To examine the expression patterns of genes involved in SA-, JA- and ABA-related plant signal transduction pathways, $N$. benthamiana leaf samples were collected at various time points after treatments. RNA was isolated from leaves at 0,6 and $12 \mathrm{hrs}$ after inoculation with Pst $\mathrm{T} 1+$ Pstab extracts (Pstab ext./Pst T1) or with Pst T1 + MG medium extracts as control (MG ext./Pst T1). All RNA samples were extracted using Qiagen RNeasy Mini Kit (Qiagen, Valencia Calif.), and cDNA was synthesized using Superscript III reverse transcriptase (Invitrogen, Grand Island, N.Y.). Quantification and purity of RNA and cDNA were determined using NanoDrop (Thermo Scientific, Wilmington, Del.). Expressions of PR1, PR2, PR5, PDF1.2, ABA1, and COI1, representative genes for each ABA, SA and JA signal pathway, and HSR203J for HR cell death, were determined by quantitative real-time PCR. At least three biological replicates of each sample and three technical replicates of each biological replicate were analyzed for real-time PCR analysis. The amount of transcripts for each gene in different RNA samples was normalized with the transcripts of the internal control gene NbActin to ensure an equal amount of cDNA was used for individual reactions.

\section{Additional files}

Additional file 1: Table S1. List of extracellular metabolites secreted from P. syringae pv. tabaci using UHPLC-qTOF-MS.

Additional file 2: Figure S1. Expression patterns of $P R 5, P D F 1.2, A B A 1$, HSR203J and COII genes after treating with MG or Pstab extracts in N. benthamiana. The expression level of PR5, PDF1.2, ABA1, HSR203J and COl1 as determined by qRT-PCR after treatment of Pstab extracts. Gene expression analyses were performed using three biological replications. Bars represent the means \pm standard deviation (SD). Same letters above bars indicate no statistically significant difference $(P<0.05)$ among plant genotypes for a given time point using one-way ANOVA followed by LSD test analysis. The qRT-PCR data were normalized to NbActin transcript and shown as relative to that of target gene expressions in $0 \mathrm{hr} N$. benthamiana leaves without any treatment.

\section{Competing interests}

The authors declare that they don't have any competing interests.

\section{Authors' contributions}

SL performed major parts of the experiments; DY prepared Pstab extracts and carried out mass-spectrometry analysis for Pstab extracts; SRU carried out confocal images of GFPuv-expressing bacteria in stomata and apoplast space; LWS designed bacterial metabolomics work and edited this manuscript; KSM participated in designing and coordinating the project. SL and KM wrote the manuscript. All authors read and approved the final manuscript.

\section{Acknowledgements}

This study was supported by The Samuel Roberts Noble Foundation. The authors thank Pierce Young (Texas A\&M University) for technical assistance during the 2011 Noble Foundation summer intern program, Mr. David Huhman for performing the UHPLC-qTOF-MS analyses and Hee-Kyung Lee for RNA sample preparations. We also thank Janie Gallaway and Colleen Elles for greenhouse support and Jackie Kelley for manuscript editing.

Received: 21 November 2012 Accepted: 13 April 2013

Published: 18 April 2013

\section{References}

1. Hirano SS, Upper CD: Population biology and epidemiology of Pseudomonas syringae. Annu Rev Phytopathol 1990, 28:155-177.

2. Melotto M, Underwood W, Koczan J, Nomura K, He SY: Plant stomata function in innate immunity against bacterial invasion. Cell 2006, 126(5):969-980.

3. Melotto M, Underwood W, He SY: Role of stomata in plant innate immunity and foliar bacterial diseases. Annu Rev Phytopathol 2008, 46:101-122.

4. Heath MC: Hypersensitive response-related death. Plant Mol Biol 2000, 44(3):321-334.

5. Underwood W, Melotto M, He SY: Role of plant stomata in bacterial invasion. Cell Microbiol 2007, 9(7):1621-1629.

6. Boller T, Felix G: A renaissance of elicitors: perception of microbeassociated molecular patterns and danger signals by pattern-recognition receptors. Annu Rev Plant Biol 2009, 60:379-406.

7. Bender $\mathrm{CL}$, Alarcon-Chaidez F, Gross DC: Pseudomonas syringae phytotoxins: mode of action, regulation, and biosynthesis by peptide and polyketide synthetases. Microbio/ Mol Biol Rev 1999, 63(2):266-292.

8. Cintas NA, Koike ST, Bull CT: A new pathovar, Pseudomonas syringae pv. alisalensis, proposed for the causal agent of bacterial blight of broccoli and broccoli raab. Plant Disease 2002, 86:992-998.

9. Feys B, Benedetti CE, Penfold CN, Turner JG: Arabidopsis mutants selected for resistance to the phytotoxin coronatine are male sterile, insensitive 
to methyl jasmonate, and resistant to a bacterial pathogen. Plant Cell 1994, 6(5):751-759.

10. Zhao Y, Thilmony R, Bender CL, Schaller A, He SY, Howe GA: Virulence systems of Pseudomonas syringae pv. tomato promote bacterial speck disease in tomato by targeting the jasmonate signaling pathway. Plant J 2003, 36(4):485-499.

11. Uppalapati SR, Ayoubi P, Weng H, Palmer DA, Mitchell RE, Jones W, Bender $\mathrm{CL}$ : The phytotoxin coronatine and methyl jasmonate impact multiple phytohormone pathways in tomato. Plant J 2005, 42(2):201-217.

12. Zeng W, He SY: A prominent role of the flagellin receptor FLAGELLINSENSING2 in mediating stomatal response to Pseudomonas syringae pv tomato DC3000 in Arabidopsis. Plant Physiol 2010, 153(3):1188-1198.

13. Zeng W, Brutus A, Kremer JM, Withers JC, Gao X, Jones AD, He SY: A genetic screen reveals Arabidopsis stomatal and/or apoplastic defenses against Pseudomonas syringae pv. tomato DC3000. PLoS Pathog 2011, 7(10):e1002291.

14. Gudesblat GE, Torres PS, Vojnov AA: Xanthomonas campestris overcomes Arabidopsis stomatal innate immunity through a DSF cell-to-cell signalregulated virulence factor. Plant Physiol 2009, 149(2):1017-1027.

15. Mysore KS, Ryu CM: Nonhost resistance: how much do we know? Trends Plant Sci 2004, 9(2):97-104

16. Preston GM, Bertrand N, Rainey PB: Type III secretion in plant growthpromoting Pseudomonas fluorescens SBW25. Mol Microbiol 2001, 41(5):999-1014.

17. Alfano JR, Collmer A: Type III secretion system effector proteins: double agents in bacterial disease and plant defense. Annu Rev Phytopathol 2004, 42:385-414.

18. Lindgren PB: The role of hrp genes during plant-bacterial interactions. Annu Rev Phytopathol 1997, 35:129-152.

19. Abramovitch RB, Kim YJ, Chen S, Dickman MB, Martin GB: Pseudomonas type III effector AvrPtoB induces plant disease susceptibility by inhibition of host programmed cell death. EMBO J 2003, 22:60-69.

20. Jamir Y, Guo M, Oh HS, Petnicki-Ocwieja T, Chen S, Tang X, Dickman MB, Collmer A, Alfano JR: Identification of Pseudomonas syringae type III effectors that can suppress programmed cell death in plants and yeast. Plant J 2004, 37(4):554-565.

21. Lin NC, Martin GB: An avrPto/avrPtoB mutant of Pseudomonas syringae pv. tomato DC3000 does not elicit Pto-mediated resistance and is less virulent on tomato. Mol Plant Microbe Interact 2005, 18(1):43-51.

22. Kang L, Tang X, Mysore KS: Pseudomonas Type III effector AvrPto suppresses the programmed cell death induced by two nonhost pathogens in Nicotiana benthamiana and tomato. Mol Plant Microbe Interact 2004, 17(12):1328-1336.

23. Lee S, Ishiga Y, Clermont K, Mysore KS: Coronatine inhibits stomatal closure and delays hypersensitive response cell death induced by nonhost bacterial pathogens. PeerJ 2013, 1:e34

24. Wang K, Kang L, Anand A, Lazarovits G, Mysore KS: Monitoring in planta bacterial infection at both cellular and whole-plant levels using the green fluorescent protein variant GFPuv. New Phytol 2007, 174(1):212-223.

25. Bogdanove AJ, Martin GB: AvrPto-dependent Pto-interacting proteins and AvrPto-interacting proteins in tomato. Proc Natl Acad Sci 2000 97(16):8836-8840.

26. De Wit PJGM: Pathogen avirulence and plant resistance: a key role for recognition. Trends Plant Sci 1997, 2(12):452-458.

27. Kanneganti TD, Huitema E, Cakir C, Kamoun S: Synergistic interactions of the plant cell death pathways induced by Phytophthora infestans Nepllike protein PiNPP1.1 and INF1 elicitin. Mol Plant Microbe Interact 2006 19(8):854-863.

28. Pontier D, Godiard L, Marco Y, Roby D: hsr203J, a tobacco gene whose activation is rapid, highly localized and specific for incompatible plant/ pathogen interactions. Plant J 1994, 5(4):507-521.

29. Beattie GA, Lindow SE: The secret life of foliar bacterial pathogens on leaves. Annu Rev Phytopathol 1995, 33:145-172.

30. Chinchilla D, Bauer Z, Regenass M, Boller T, Felix G: The Arabidopsis receptor kinase $F L S 2$ binds flg22 and determines the specificity of flagellin perception. Plant Cell 2006, 18(2):465-476.

31. Chisholm ST, Coaker G, Day B, Staskawicz BJ: Host-microbe interactions: shaping the evolution of the plant immune response. Cell 2006 124(4):803-814.

32. Cui J, Bahrami AK, Pringle EG, Hernandez-Guzman G, Bender CL, Pierce NE, Ausubel FM: Pseudomonas syringae manipulates systemic plant defenses against pathogens and herbivores. Proc Natl Acad Sci U S A 2005 102(5):1791-1796.

33. Mittal S, Davis KR: Role of the phytotoxin coronatine in the infection of Arabidopsis thaliana by Pseudomonas syringae pv. tomato. Mol Plant Microbe Interact 1995, 8(1):165-171.

34. Budde IP, Ullrich MS: Interactions of Pseudomonas syringae pv. glycinea with host and nonhost plants in relation to temperature and phytotoxin synthesis. Mol Plant Microbe Interact 2000, 13(9):951-961.

35. Brooks DM, Bender CL, Kunkel BN: The Pseudomonas syringae phytotoxin coronatine promotes virulence by overcoming salicylic acid-dependent defences in Arabidopsis thaliana. Mol Plant Pathol 2005, 6(6):629-639.

36. Mitchell RE: Implications of toxins in the ecology and evolution of plant pathogenic microorganisms: bacteria. Experientia 1991, 47:791-803.

37. Turner JG, Debbage JM: Tabtoxin-induced symptoms are associated with accumulation of ammonia formed during photorespiration. Physiol Plant Pathol 1982, 20:223-233.

38. Bender CL: Chlorosis-inducing phytotoxins produced by Pseudomonas syringae. European J Plant Pathology 1999, 105:1-12.

39. Raaijmakers JM, de Bruijn I, de Kock MJ: Cyclic lipopeptide production by plant-associated Pseudomonas spp.: diversity, activity, biosynthesis, and regulation. Mol Plant Microbe Interact 2006, 19(7):699-710.

40. Lee DL, Rapoport H: Synthesis of tabtoxinine- $\delta$-lactam. J Org Chem 1975 , 40:3491-3495

41. Hwang MS, Morgan RL, Sarkar SF, Wang PW, Guttman DS: Phylogenetic characterization of virulence and resistance phenotypes of Pseudomonas syringae. Appl Environ Microbiol 2005, 71(9):5182-5191.

42. Mitchell RE: Isolation and structure of a chlorosis inducing toxin of Pseudomonas phaseolicola. Phytochemistry 1976, 15:1941-1947.

43. UT F, Durbin RD: Hydrolysis of tabtoxins by plant and bacterial enzymes. Experientia 1980, 36:301-302.

44. Ewald JC, Heux S, Zamboni N: High-throughput quantitative metabolomics: workflow for cultivation, quenching, and analysis of yeast in a multiwell format. Anal Chem 2009, 81(9):3623-3629.

45. Alvarez ME: Salicylic acid in the machinery of hypersensitive cell death and disease resistance. Plant Mol Biol 2000, 44:429-442.

46. Yan J, Zhang C, Gu M, Bai Z, Zhang W, Qi T, Cheng Z, Peng W, Luo H, Nan $\mathrm{F}$, et al: The Arabidopsis CORONATINE INSENSITIVE1 protein is a jasmonate receptor. Plant Cell 2009, 21(8):2220-2236.

47. Bari $\mathrm{R}$, Jones JDG: Role of plant hormones in plant defence responses. Plant Mol Biol 2009, 69:473-488.

48. Pacheco R, Garcia-Marcos A, Manzano A, de Lacoba MG, Camanes G, GarciaAgustin P, Diaz-Ruiz JR, Tenllado F: Comparative analysis of transcriptomic and hormonal responses to compatible and incompatible plant-virus interactions that lead to cell death. Mol Plant Microbe Interact 2012, 25(5):709-723

49. Devadas SK, Enyedi A, Raina R: The Arabidopsis hrl1 mutation reveals novel overlapping roles for salicylic acid, jasmonic acid and ethylene signalling in cell death and defence against pathogens. Plant J 2002, 30(4):467-480

50. Nüske J, Bublitz F: In vitro coronatine production by several Pseudomonas syringae pv. glycinea isolates. J Basic Microbiol 1993, 33:241-246.

51. Tang X, Frederick RD, Zhou J, Halterman DA, Jia Y, Martin GB: The avirulence protein AvrPto physically interacts with the Pto kinase. Science 1996, 274:2060-2063.

52. Van der Hoorn RA, Laurent F, Roth R, De Wit PJ: Agroinfiltration is a versatile tool that facilitates comparative analyses of Avr9/Cf-9-induced and Avr4/Cf-4-induced necrosis. Mol Plant Microbe Interact 2000, 13(4):439-446

doi:10.1186/1471-2229-13-65

Cite this article as: Lee et al:: Suppression of plant defense responses by extracellular metabolites from Pseudomonas syringae pv. tabaci in Nicotiana benthamiana. BMC Plant Biology 2013 13:65. 